AWEJ for Translation \& Literary Studies, Volume3, Number4. October 2019

Pp.118-129

DOI: http://dx.doi.org/10.24093/awejtls/vol3no4.10

\title{
Errors in Arabic-English Translation among Saudi Students: Comparative Study Between Two Groups of Students
}

\author{
Islam Ababneh \\ Department of English, University of Hafr Al Batin \\ Saudi Arabia
}

\begin{abstract}
The main objective of this paper is to identify the translational errors made by Arab natives. The study is an Arabic to English translational skills' comparison between two Saudi groups in two separate areas of Saudi Arabia: Tabuk and Hafr Al Batin. The study investigated how Arabic cultural, religious, and other factors influenced the production of such errors by the two groups. Each group consisted of selected female students majoring in the English language and attending two regional universities. The students were all of the Saudi nationality and they had obtained their school education within their region before joining a public university. A newly designed quiz was attempted by the students in each group to translate words and phrases categorized into four parts: syntax, spelling, word choice, and singular/plural. It was concluded that lack of English knowledge, unfamiliarity with some English terms, cultural and religious factors, and literal translation are the leading causes of wrong translations. Also, the Tabuk students slightly performed better than Hafr Al Batin students; and this is maybe due to better literacy infrastructure in the city of Tabuk, vibrant cultural diversity in the city with more expatriates working and residing in the region and having more private schools.
\end{abstract}

Keywords: Arabic, English, Saudi Arabia, Translation

Cites as: Ababneh, I. (2019). Errors in Arabic-English Translation among Saudi Students: Comparative Study Between Two Groups of Students. Arab World English Journal for Translation \& Literary Studies3 (4)118-129. DOI: http://dx.doi.org/10.24093/awejtls/vol3no4.10 